\title{
A TUTELA AO MEIO AMBIENTE EQUILIBRADO SOB A ÉGIDE DA CONVENÇÃO SOBRE A DIVERSIDADE BIOLÓGICA, E A PROTEÇÃO JURÍDICA NA CONSTITUIÇÃO FEDERAL DE 1988
}

\section{THE PROTECTION TO BALANCED ENVIRONMENT UNDER THE CONVENTION ON BIOLOGICAL DIVERSITY AEGIS AND LEGAL PROTECTION IN THE FEDERAL CONSTITUTION OF 1988}

Domingos Benedetti Rodrigues ${ }^{1}$

Denise Tatiane Girardon dos Santos ${ }^{2}$

\begin{abstract}
Resumo: Diante do avanço e do progresso tecnológicos e do crescimento demográfico acentuado, houve o despertar da humanidade para uma questão, extremamente, preocupante, que é a preservação do meio ambiente como requisito para se garantir a própria sobrevivência. Para tanto, várias foram as medidas adotadas, mormente, em nível internacional, destacando-se a edição da Convenção sobre a Diversidade Biológica, após um longo percurso histórico na busca da efetivação dessa proteção. Logo, o presente trabalho tem, por objetivo, identificar as principais previsões, elencadas em tal Documento, com a finalidade de se promover a preservação da diversidade biológica por meio da utilização sustentável dos recursos naturais; bem como, discorrer sobre as medidas, previstas, constitucionalmente, no Brasil, a fim de concretizar as premissas, contidas na Convenção sobre a Diversidade Biológica.
\end{abstract}

Palavras-Chave: Convenção. Constituição. Diversidade biológica. Desenvolvimento sustentável. Preservação ambiental.

Abstract: Given the advancement and technological progress and high population growth, there was the awakening of humanity to a question, extremely worrying, which is the preservation of the environment as a requirement to ensure their own survival. To this end, several measures have been adopted, especially at the international level, highlighting the issue of the Convention on Biological Diversity, after a long historical journey in search of the

\footnotetext{
${ }^{1}$ Doutorando em Educação nas Ciências pela Universidade Regional do Noroeste do Estado do Rio Grande do Sul - UNIJUÍ; vinculado ao sistema de TAXAS da CAPES. Mestre em Direitos Sociais e Políticas Públicas pela Universidade de Santa Cruz do Sul - UNISC. Bacharel em Ciências Jurídicas e Sociais. Contato: mingojuslex@yahoo.com.br.

${ }^{2}$ Doutoranda em Direito, linha de concentração em Direito Público, pela Universidade do Rio dos Sinos UNISINOS. Mestra em Direito, linha de concentração em Direitos Humanos, pela Universidade Regional do Noroeste do Estado do Rio Grande do Sul - UNIJUÍ. Especialista em Educação Ambiental pela Universidade Federal de Santa Maria - UFSM. Bacharel em Direito pela Universidade de Cruz Alta - UNICRUZ. Docente nos cursos de Direito da UNICRUZ e das Faculdades Integradas Machados de Assis - FEMA. Advogada. Contato: dtgsjno@hotmail.com.
} 
effectiveness of this protection. Therefore, the present study has aimed to identify the main predictions, listed in this document, in order to promote the conservation of biological diversity through sustainable use of natural resources; as well as discuss the measures contemplated, constitutionally, in Brazil, in order to realize the assumptions contained in the Convention on Biological Diversity.

Keywords: Convention. Constitution. Biological diversity. Sustainable development. Environmental Conservation.

\section{CONSIDERAÇÕES INICIAIS}

Em razão da premente necessidade de se tutelar o meio ambiente, de modo equilibrado e sustentável, este trabalho visa a promover uma abordagem sobre os principais eventos históricos, com o foco na proteção do meio ambiente e no ecodesenvolvimento, que culminaram na elaboração da Convenção sobre a Diversidade Biológica (CDB), ratificada pelo Brasil, e que passou a vigorar em 1993 (COMUNIDADE EUROPEIA, 2006). Tal Convenção se constitui no principal Documento com fins de proteção e preservação da diversidade biológica, considerando que o desenvolvimento e o bem-estar da humanidade, com a garantia para as futuras gerações, dependem, diretamente, dessa salvaguarda.

O meio ambiente equilibrado se insere como um dos direitos humanos fundamentais, sendo que, para assegurar a concretização desse direito, a CDB objetivou a melhoria da qualidade de vida, com o crescimento econômico vinculado à conservação da diversidade biológica, o uso sustentável da biodiversidade e da divisão, de modo justo e equitativo, dos recursos biológicos, visando, com isso, a atingir um desenvolvimento sustentável, tanto ecologicamente, quando política e socialmente. Ademais, far-se-á uma abordagem a respeito da receptividade dessa Convenção pelo ordenamento pátrio brasileiro, e sobre as principais previsões constitucionais que determinam a forma de se promover a tutela do meio ambiente e a o desenvolvimento sustentável.

Delimitado o assunto, acredita-se que o estudo sobre as previsões legais, contidas na Convenção sobrea Diversidade Biológica, e imbuídas na busca pela conservação do meio ambiente equilibrado, da diversidade biológica e, consequentemente, da sustentabilidade desse meio, bem como, no seu albergamento pela Carta Magna brasileira, possa contribuir para a compreensão desse tema relevante, e, com isso, favorecer a busca pelo bem-estar da sociedade e das futuras gerações.

Versão em português recebida em 08/01/2014, aceita em 08/01/2015, e autorizada para publicação em 29/06/2015 


\section{A INTERnACIONALIZAÇÃo DA PROTEÇÃo AMBIENTAL E A BUSCA PELA SUSTENTABILIDADE}

Historicamente, com o desenvolvimento das sociedades, o ser humano passou a sustentar uma visão etnocêntrica em relação à questão ambiental, considerando-se como o ser dominante da natureza, criando uma visão fragmentada e excludente, a partir da qual se extraiu dos ecossistemas, onde estava inserido. Conforme Segura (2001), foi com supedâneo nessa visão que se desenvolveu o modelo técnico-científico, iniciando-se a degradação ambiental a partir da Revolução Industrial, no século XVIII, pois se acreditava que a natureza era uma fonte inesgotável de recursos, estes, usados com a finalidade de acúmulo de capital.

Contudo, o desenvolvimento tecnológico, o aumento do contingente populacional, a exploração demasiada dos recursos naturais, a poluição, a desigualdade social, dentre outros fatores, fizeram com que os problemas ambientais se acentuassem (ISAIA, 2004), gerando uma insustentabilidade ambiental, que, por fim, revelou a crise ambiental, inflando o surgimento de reflexões sobre a preservação dos recursos naturais em nível mundial (BRUGGER, 2004).

A partir da segunda metade do século XX, a necessidade de conservação dos recursos naturais deu causa ao movimento ambientalista, que passou a reclamar um desenvolvimento que fosse sustentável, ante o crescimento econômico mundial que desconsiderava os impactos ambientais. Como eventos, dedicados à salvaguarda ambiental, destacam-se, no plano internacional, na Conferência sobre a Biosfera, promovida pela UNESCO, em 1968, discutiuse a fundamentação científica do uso e da conservação dos recursos naturais (GANEM, 2012); em 1971, a UNESCO criou o Programa O Homem e a Biosfera, visando a engajar a comunidade científica no estudo das relações entre os seres humanos e o meio, com foco na conservação ambiental (LE PRESTE, 2000).

O Autor prossegue explicando que, com a acentuação dos problemas ambientais globais, a ONU realizou a Conferência das Nações Unidas para o Meio Ambiente Humano, em Estocolmo, no ano de 1972, objetivando ressalvar a responsabilidade do ser humano para a preservação do equilíbrio ambiental no planeta. Nessa Conferência, foram definidos vinte e seis princípios, considerando, principalmente, as desigualdades sociais entre as nações, pelo que o 
desenvolvimento econômico foi avaliado como uma pré-condição para o progresso na qualidade de vida e, consequentemente, para a redução da degradação ambiental (PASSOS, 2009).

A partir dessa época, a discussão de um modelo de desenvolvimento sustentável, que proporcionasse a continuidade da evolução industrial, tecnológica e científica, mas com a preservação do meio ambiente e com o mínimo de impacto aos recursos naturais, ou seja, a harmonização das relações econômicas com o bem-estar social, ampliou-se significativamente, passando a ser conhecida como ecodesenvolvimento, conforme denominou Ignacy Sachs (1986).

Em 1980, a União Internacional para a Conservação da Natureza (UICN) lançou a Estratégia Mundial para a Conservação, propendendo ao enfrentamento das problemáticas dos países em desenvolvimento e à conciliação dos conceitos de conservação e de desenvolvimento - sustentável. Seus princípios foram reafirmados em 1982, na Carta Mundial da Natureza, escrita pela UICN e confirmada pela ONU, avultando a necessidade de proteção dos habitats, da avaliação dos impactos ambientais e do direito à informação (QUINTÃO, 1983).

O Programa das Nações Unidas para o Meio Ambiente (PNUMA), estabelecido em 1972, pela ONU, foi criado para buscar uma conscientização ambiental e a implementação dos programas ligados a essa temática, destacando-se pela promoção e continuação das reuniões internacionais, realizadas desde a década de 80 (UNEP, 2014). No ano de 1983, a ONU criou a Comissão Mundial sobre o Meio Ambiente e o Desenvolvimento (CMED), para viabilizar o diálogo e a cooperação entre as nações sobre as questões ambientais e o desenvolvimento. Assim, em 1987, foi lavrado o Relatório Brundtland - texto preparatório à Conferência das Nações Unidas sobre o Meio Ambiente (ECO-92) - popularmente, conhecida como Nosso Futuro Comum -, onde a ideia de desenvolvimento sustentável foi amadurecida como a capacidade de garantir as necessidades das gerações futuras (ALMEIDA, 1990).

O conceito de desenvolvimento sustentável - apesar de criticado, porque seria insuficiente para a atualidade -, se apresentou como um avanço no campo das concepções de desenvolvimento e nas abordagens tradicionais, relativas à preservação dos recursos naturais, como um resgate da noção de progresso e de avanço tecnológico, socialmente, justos, economicamente, viáveis, ecologicamente, sustentáveis e, culturalmente, aceitos. O Relatório 
Brundtland, precursor da CDB, foi o primeiro documento a evidenciar que o meio ambiente e a sua qualidade são temas coletivos, pois apontam para um futuro comum da humanidade (DIEGUES, 1992).

Em 1987, houve a assinatura do Protocolo de Montreal, que tratou sobre o acúmulo de substâncias agressivas à camada de ozônio e lançou os conceitos jurídicos dos princípios da responsabilidade comum e da precaução, que, posteriormente, foram incorporados na Convenção em liça (LE PRESTE, 2000). Ainda, o Fundo Mundial para o Meio Ambiente foi instituído em 1990, com o desígnio de apoiar projetos relacionados às mudanças climáticas, à rarefação da camada de ozônio, à poluição dos oceanos e à redução da biodiversidade.

Assim, firmou-se o compromisso com o desenvolvimento sustentável, uma manifestação inquestionável da urgência em se encontrar um modo de crescimento que seja menos lesivo ao meio ambiente, e mais duradouro. Para tanto, é imperativo que os bens ambientais sejam reconhecidos como a base de sustentação de todos os seres vivos - bens coletivos -, o que levará à composição da questão ambiental, pois a compreensão da sustentabilidade do planeta depende, além da preservação dos recursos naturais, de seu uso, com reserva, e do seu acesso como direito público e universal (ISAIA, 2004).

A Convenção sobre a Diversidade Biológica, estabelecida durante o evento ECO-92 Conferência das Nações Unidas sobre Meio Ambiente e Desenvolvimento (CNUMAD), realizada no Rio de Janeiro, em junho do mencionado ano, e que passou a vigorar a partir de dezembro de 1993, é o principal Instrumento, de cunho internacional, voltado às questões relacionadas ao meio ambiente, tendo sido assinada por mais de cento e sessenta países (MMA, 2014). Os direitos, assegurados em Documentos dessa natureza, são considerados fundamentais, válidos para todas as pessoas, indistintamente, pois, como leciona Bobbio (2004), o próprio ser humano é o fundamento de todos os valores, eis que tais direitos dizem respeito ao homem e, ao mesmo tempo, ao cidadão, ainda que representados por entes coletivos, como grupos, povos ou até mesmo Estados.

O equilíbrio ambiental e a sustentabilidade se enquadram no rol de direitos humanos de terceira geração, haja vista que os direitos humanos são um edificado axiológico, uma invenção humana em constante processo de construção e reconstrução, fundamentado em um espaço simbólico de luta e ação social (ARENDT, 1979). Nesse entendimento, a proteção do meio 
ambiente exigia uma normatização que extrapolasse fronteiras, posto que inserta a todas as pessoas pela própria natureza humana, visando a assegurar a liberdade e, assim, igualdade. Nas palavras de Mancini (2003, p. 68):

Se é Direito tudo aquilo que responde à natureza e ao destino dos seres livres, sociáveis e imputáveis, é evidente que da natureza, do constante e harmônico desenvolvimento, do visível progresso das nacionalidades coexistentes e de toda espécie humana, se deduz e se demonstra a lei jurídica que preside a grande sociedade das nações.

As reflexões sobre as circunspectas consequências da exploração descomedida do meio ambiente natural permitiram a divulgação da necessidade de proteção e conservação da natureza e da restauração dos espaços destruídos, para afiançar a perpetuação de um ambiente saudável e adequado para o desenvolvimento de todos os seres vivos (LAYRARGUES, 1997). Por isso, o meio ambiente equilibrado é um direito humano fundamental, e, ante a finitude dos recursos naturais, as preocupações com a sua preservação se transformaram em verdadeiros desafios, comuns à humanidade, exigindo a colaboração de todos para a implementação do ecodesenvolvimento e do bem-estar social.

\section{A CONVENÇÃO SOBRE A DIVERSIDADE BIOLÓGICA: ASPECTOS GERAIS}

A superioridade do Direito Internacional é imperativa, pois subordina os Estados a uma ordem jurídica supranacional que visa a tutelar os direitos e garantias básicos das pessoas, em função de sua dignidade. Nessa perspectiva, a CDB se constitui em uma norma peremptória, com força de obrigar os Estados-Membros, devido à importância de sua matéria, e, portanto, de regular, de modo decisivo, a questão da proteção ao meio ambiente e da promoção do desenvolvimento sustentável no espaço jurídico internacional.

Os objetivos sociais dessa Convenção são, consoante Cunha (2004, p. 39) “[...] a conservação da diversidade biológica, o uso sustentável de suas partes constitutivas e a repartição justa e equitativa dos benefícios que advém do uso dos recursos genéticos [...]", além da melhoria da qualidade de vida e do fim da pobreza, que devem ser perseguidos com base numa estratégia operacional de crescimento econômico. A Convenção consagrou dois princípios importantes no Direito Internacional, que é o das responsabilidades comuns - todos Versão em português recebida em 08/01/2014, aceita em 08/01/2015, e autorizada para publicação em 29/06/2015 
os países possuem a obrigação de preservarem a biodiversidade e de cooperarem para a proteção ambiental - e o da precaução - a ausência de certeza científica sobre os danos ambientais, advindos de uma atividade, não significa que tais não devam ser evitados, ou mitigados (ANTUNES, 2008).

Nessa seara, oportuno definir desenvolvimento e sustentabilidade. Segundo Mendes (1993), desenvolvimento significa crescimento econômico, e sustentabilidade, basicamente, a ecologia - não política social. Contudo, o termo sustentabilidade, para a acepção de desenvolvimento sustentável, conceitua-se como sustentabilidade ecológica, política e social, com enfoque na racionalidade ambiental e no encalce por estratégias para se atingir a sustentabilidade.

O termo biodiversidade foi usado pelo biólogo Edward Wilson, na década de 80, e, na perspectiva científica, significa a totalidade da variedade de vida, estudada em três níveis: ecossistemas, espécies e genes (WILSON, 1997). Atualmente, consubstancia-se em um termo empregado para expressar a diversidade de seres vivos, de florestas e/ou de mudanças climáticas, o que pode ser um ponto negativo na medida em que obscurece a noção exata de biodiversidade (LE GUYADER, 2008).

A noção de sustentabilidade funda-se em, pelo menos, dois critérios: as ações humanas são ponderadas quanto à incidência das consequências diante do tempo cronológico, pois os efeitos são analisados no presente e no futuro; bem como, ao se elaborar um prognóstico do futuro, é necessária a pesquisa sobre quais efeitos continuarão, e suas consequências. Portanto, o conceito de sustentabilidade passa a qualificar, ou caracterizar, o desenvolvimento (MACHADO, 2013).

A diversidade biológica, por ser um recurso natural, também é um bem ambiental; por decorrência, tornar-se um bem jurídico, que necessita de tutela para ter assegurada a sua continuidade, pois, do contrário, poderia ser explorada, indiscriminadamente, até o completo esgotamento. Derani (1997) expõe que diversidade biológica é o termo usado para designar toda a variedade de formas de vida, além de versar sobre as diferenças genéticas das espécies e a variabilidade de ecossistemas. Santos et. al (2005) apontam que o termo biodiversidade designa, também, os conhecimentos sobre essa diversidade, ainda que não seja possível ter o conhecimento, com exatidão, de qual o número de espécies vivas existentes. 
A combinação das formas de vida e sua interação com o meio ambiente representa a biodiversidade, que provê o sustento da vida humana. Logo, tal Convenção possui, como supedâneo, a conservação da diversidade biológica, o uso sustentável da biodiversidade e a repartição, de forma justa e igualitária, dos benefícios provenientes da utilização dos recursos biológicos. A CDB dividiu a biodiversidade em três níveis: ecossistemas, espécies e recursos genéticos, abrangendo todos os pontos e questões que possam vir, direta ou indiretamente, a se relacionar com ela, se constituindo em um arcabouço legal e político para a produção de várias convenções e acordos ambientais pontuais.

Especificamente, sobre a premissa que trata do uso sustentável da biodiversidade, já em seu Preâmbulo se verifica a preocupação em relação ao valor social e econômico da diversidade biológica (VARELLA; ROCHA, 1999), ante o fato de a conservação desta implicar no bemestar de toda a humanidade. Com isso, a Convenção manifesta a preocupação com a redução, ou a perda, da diversidade e de seus recursos, destacando a necessidade de cooperação internacional para aproveitá-los de forma sustentável. Cenci (2012, p. 38) salienta a proeminência da CDB e da cooperação entre os povos como forma de se atingir a sustentabilidade:

\begin{abstract}
Logo, A declaração do Rio de Janeiro foi além da afirmação do direito ao meio ambiente ecologicamente equilibrado como direito fundamental, identificando que o direito ao ambiente sadio já havia sido reconhecido nacional, regional e internacionalmente. Estabeleceu que, reconhecendo e operacionalizando o direito a um ambiente saudável, dever-se-ia ir além dos conceitos reducionistas de homem antes ou ecologia antes, e construir um amálgama de objetivos comuns de desenvolvimento e proteção ambiental.
\end{abstract}

Ainda que as nações gozem de soberania na exploração de seus recursos naturais e que tenham assumido a responsabilidade de assegurar que as suas atividades não sejam prejudiciais ao meio ambiente de outros Estados, as questões relacionadas com a proteção da biodiversidade ultrapassam as fronteiras nacionais, devendo ser uma preocupação de todos. Para a concretização dessas medidas, a CDB previu a criação de um Secretariado, imbuído de organizar as sessões conferenciais das Partes, preparar relatórios sobre o seu desempenho funcional e participar da coordenação conjunta com outros organismos internacionais (artigo 24); também, o Órgão Subsidiário de Assessoramento Científico, Técnico e Tecnológico, para 
buscar a efetivação das previsões (artigo 25). Assim, os Estados-Membros devem, periodicamente, apresentar Relatórios sobre as medidas adotadas para a implementação dos dispositivos do Documento em liça, e sobre sua eficácia (artigo 26) (MMA, 2014).

Tais medidas são previstas com a finalidade de que a sua prática levará à autossustentabilidade econômica dos países, revelando-se, não somente, em uma oportunidade para a preservação das diversidades, mas, também, como primordial para a consecução dos objetivos de desenvolvimento sustentável da sociedade (SEM, 1999). Isso reflete o progresso quanto à proteção da diversidade biológica, e, consequentemente, da sustentabilidade, incluindo, na pauta de discussões, as questões ambientais, além dos problemas relativos à pobreza e ao desenvolvimento socioeconômico, passando a serem, também, prioridades dos governos.

Ainda, a Convenção elencou duas estratégias principais para que as futuras gerações possam usufruir do meio: as conservações in $s i t u^{3}$ e $e x s i t u^{4}$, sendo a primeira a proteção da biodiversidade em todos os seus componentes, competindo aos Estados Membros a sua manutenção; a segunda, a manutenção de componentes da diversidade biológica fora de seus hábitats naturais, com a mesma obrigatoriedade aos Estados ratificadores (GANEM, 2012).

A sustentabilidade, com o uso responsável das fontes naturais, é apontada como o meio pelo qual se atingirá o desenvolvimento econômico e social e, por consequência, o desarraigamento da pobreza, pois possibilitará o atendimento das necessidades da população mundial (COMISSÃO EUROPEIA, 2006). Assim, vem a ser, ao mesmo tempo, a rejeição do desenvolvimento anacrônico e do ambientalismo pueril, pois o desenvolvimento somente poderá ocorrer ao se considerar a questão intergeracional e a busca pela erradicação das desigualdades (SOUZA; DAL RI, 2012), pelo que a CDB (MMA, 2014, p. 10) conceituou utilização sustentável, em seu artigo $3^{\circ}$, como:

[...] a utilização de componentes da diversidade biológica de modo e em ritmo tais que não levem, no longo prazo, à diminuição da diversidade biológica, mantendo assim seu potencial para atender as necessidades e aspirações das gerações presentes e futuras.

\footnotetext{
${ }^{3}$ Expressão, da Língua Latina, que significa "no lugar".

${ }^{4}$ Expressão, da Língua Latina, que significa "fora do lugar".

Versão em português recebida em 08/01/2014, aceita em 08/01/2015, e autorizada para publicação em 29/06/2015
} 


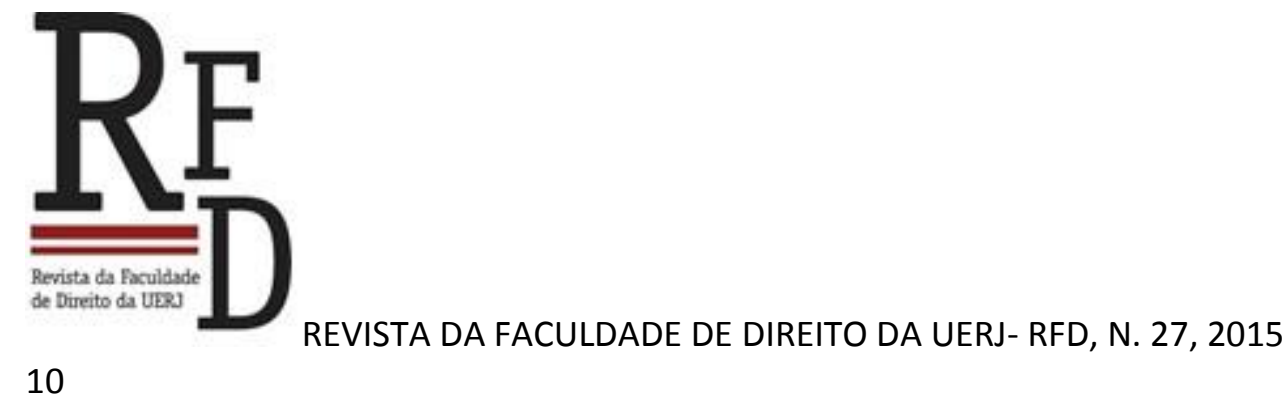

Para a concretização desse objetivo, restou estipulada a obrigatoriedade, por parte dos Estados-Membros, do atendimento às medidas gerais para a conservação da diversidade biológica, a partir do desenvolvimento de estratégias, com a identificação dos componentes cruciais para sua conservação e sua utilização sustentável.

A Convenção sobre a Diversidade Biológica, assim, viabiliza o ecodesenvolvimento na medida em que prevê medidas para que os recursos naturais sejam utilizados de forma racional, com a preservação do meio ambiente, dos habitats e ecossistemas, além de possuir repartições dedicadas à fiscalização do cumprimento das responsabilidades, assumidas pelos Estados ratificadores. Sua importância é insuflada porque atinge um número expressivo de nações, tanto as em desenvolvimento como as desenvolvidas, e viabiliza ações conjuntas, favorecendo o desenvolvimento sustentável dos países a partir do combate às causas da crise ambiental, possibilitando um ambiente mais saudável e o bem-estar às sociedades.

\section{A RECEPÇÃO, PELA CONSTITUIÇÃO FEDERAL DE 1988, DA CONVENÇÃO SOBRE A DIVERSIDADE BIOLÓGICA, E A POSITIVAÇÃo DA SALVAGUARDA AMBIENTAL}

Inicialmente, cumpre ressaltar que o Brasil é signatário das principais Declarações e Pactos internacionais, demonstrando ampla receptividade a esses Documentos, que se caracterizam, principalmente, pelo modo consensual como são elaborados pela Organização das Nações Unidas (ONU), possuindo implicância direta no combate às desigualdades, com a finalidade de proteção e promoção dos direitos humanos e do desenvolvimento (BRASIL, 2011).

A Constituição Federal de 1988, diferentemente, de suas antecessoras, irrompeu com grandes inovações, principalmente, na área da proteção aos direitos da pessoa humana, buscando assegurar, de forma ampla, e nas mais variadas situações, a garantia dos direitos fundamentais, que toda pessoa é dotada. Conforme discorre Santilli (2006, p. 181) "[...] é a primeira Constituição brasileira a elencar o princípio da prevalência dos direitos humanos, como o princípio fundamental a reger o Estado nas relações internacionais". 


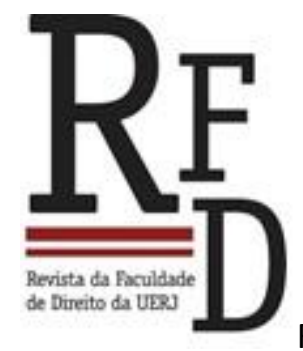

11

REVISTA DA FACULDADE DE DIREITO DA UERJ- RFD, N. 27, 2015

Logo, a partir da via da norma constitucional, com a assinatura, pelo Brasil, da Convenção sobre a Diversidade Biológica, em 05 de junho de 1992, e a promulgação, por meio do Decreto $\mathrm{n}^{\circ}$. 2.519, de 16 de março de 1998, o meio ambiente é alçado ao ponto máximo do ordenamento jurídico pátrio, sendo considerado um bem de uso comum do povo, essencial à salutar qualidade de vida, definido como um macro bem, unitário e interligado, de natureza incorpórea e imaterial, pertencente à coletividade (CANOTILHO; LEITE, 2007).

Na Carta Magna, tal premissa está elencada no artigo 225, caput, que assegura a todos o direito ao gozo de um meio ambiente equilibrado, determinando a obrigação de todos para essa manutenção/busca, a fim de assegurar às coletividades, atuais e futuras, qualidade de vida e bem-estar (BRASIL, 2014). Esse dispositivo de lei define o meio ambiente, ecologicamente, equilibrado, como um dos direitos elencados no rol do artigo $5^{\circ}$, abarcando os direitos basilares das pessoas, frente as suas posições jurídicas - individual, coletiva ou social; ainda, em sentido material, como sendo os que, mesmo não constantes no rol do referido artigo, mereçam, por conta de seu conteúdo e relevância, a equiparação aos direitos formais fundamentais (BRAUN, 2002).

A questão ambiental não é tratada, apenas, no Capítulo VI da Constituição, destinado ao Meio Ambiente, mas está presente em diversos dispositivos, como nos que tratam de questões relacionadas à economia, ao desenvolvimento agrário, à valorização das práticas culturais, evidenciando que as políticas públicas ambientais devem ser transversais. Conforme Panneton (1994), a diversidade biológica se constitui na coletiva herança biofísica, sendo o sustentáculo para a qualidade de vida, motivo pelo qual, tanto a Convenção em liça, quanto a Carta Federativa visam à proteção e/ou o restabelecimento dessa diversidade; contudo, tal recurso é deteriorável e degradável, necessitando ser gerenciado, pois a concepção do ambiente se traduz na necessidade de serem tomadas deliberações com fins de afiançá-lo, inclusive, para as futuras gerações.

Esse é um dos motivos pelos quais a Convenção sobre a Diversidade Biológica previu o incentivo à utilização dos recursos biológicos de acordo com as práticas tradicionais, de forma sustentável. Assim, crucial o apoio, também, às populações que mantêm e desenvolvem os conhecimentos do trato da natureza de forma salutar, posto que esses saberes podem ser utilizados como medidas corretivas em áreas degradadas, isso, por meio da conscientização Versão em português recebida em 08/01/2014, aceita em 08/01/2015, e autorizada para publicação em 29/06/2015 
social da importância vital da conservação de tal recurso (CUNHA, 2004). É nesse sentido que o artigo 225, inciso I da Carta Magna, prevê a preservação e a restauração dos processos ecológicos essenciais, além de determinar o manejo ecológico das espécies e ecossistemas, valorizando e relacionando os conhecimentos regionais para que sejam instrumentos de preservação da natureza (BRASIL, 2014).

Por conseguinte, o meio salutar se traduz no bem-estar das pessoas, ou seja, físico, mental e social, de modo que a sustentabilidade se apresenta como a alternativa viável para atingi-lo, nas várias searas, pois, somente com a preservação e o uso racional dos recursos biológicos é que se poderá garantir, no presente e para o futuro, o estado de bem-estar (CAMPOS, 2006). A Constituição Federal, ao afirmar a preservação do meio ambiente, inclusive, para que as futuras gerações possam usufruir de qualidade de vida, elencou o princípio da equidade intergeracional, abarcando as gerações atuais e as que virão, justificando a necessidade da preservação e da sustentabilidade. Santilli (2006, p. 188) explica:

\begin{abstract}
A Constituição reconhece, ainda, o princípio da equidade intergeracional, fundamentado no direito intergeracional - das presentes e das futuras gerações - ao ambiente sadio. Pela primeira vez, são assegurados direitos a gerações que ainda não existem, e tais direitos restringem e condicionam a utilização e o consumo dos recursos naturais pelas presentes gerações, bem como as políticas públicas a serem adotadas pelo Estado, que deverão considerar sempre a sustentabilidade dos recursos naturais a longo prazo.
\end{abstract}

Nesse ponto, o artigo 225 da Carta Magna enfatiza, no parágrafo $4^{\circ}$, a necessidade da preservação da integridade do patrimônio genético e a proteção da fauna e da flora, motivo pelo qual a Floresta Amazônica brasileira, a Mata Atlântica, a Serra do Mar, o Pantanal MatoGrossense e a Zona Costeira se constituem em patrimônio nacional, e a sua utilização deve ser regulada por legislação específica, com a observância da preservação desses ambientes, inclusive, quanto aos seus recursos naturais (CORREA, et. al, 2007).

Especificamente, quara a preservação da integridade do patrimônio genético, previu-se que deve ser promovida uma efetiva fiscalização das entidades dedicadas à pesquisa e à manipulação de material genético, nos termos do inciso II do artigo 225; bem como, sobre o patrimônio geológico, o estabelecimento da obrigação, daquele que explorar recursos minerais, 


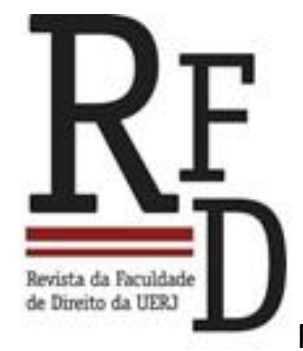

13

REVISTA DA FACULDADE DE DIREITO DA UERJ- RFD, N. 27, 2015

de recuperar o meio ambiente degradado, de acordo com solução técnica exigida pelo órgão competente (parágrafo $2^{\circ}$ ) (BRASIL, 2014).

Por isso, a opção pela sustentabilidade e pelo ecodesenvolvimento se traduz na adoção de se conservar mais capital natural para futuras gerações, o que reflete uma questão de ética social, eis que envolve distribuição de riqueza numa dimensão temporal. Todavia, para ser sustentável, o processo de desenvolvimento deve plagiar, ao máximo, os processos da natureza, com eficiência ecológica - ou economia conservativa (BRANCO, 1989). Nesse ponto, Capra (2006) afirma que os ciclos ecológicos laboram como se fossem laços de realimentação, possibilitando à comunidade ecológica estar em constante autorregulação e autoorganização; acaso uma conexão de um ciclo ecológico é perturbada, ultrapassando os limites, todo o sistema poderá ruir, pois não conseguirá mais atingir a compensação.

Portanto, é incomensurável a conservação do meio ambiente equilibrado, da diversidade biológica e, consequentemente, da sustentabilidade desse meio, para que a humanidade possa usufruir do bem-estar social, econômico, e de esses serem tratados como uma questão de direito intergeracional. Para que haja o engajamento de todos os setores da sociedade na perseguição do desenvolvimento sustentável, igualitário, economicamente, eficiente e, politicamente, possível, a participação de todos é imprescindível, pois com a aliciação das pessoas com a questão ecológica, um sentimento de responsabilidade quanto às escolhas aflorará, ante os balizamentos éticos e os juízos de valores especificados (CAVALCANTI, 1997).

Por isso, a Carta Federativa consagrou os princípios da obrigatoriedade da intervenção do Poder Público em todos os níveis e instâncias, com atuação de fomento, mas, também, de forma preventiva e reparatória dos danos ambientais (MACHADO, 2003); igualmente, os da participação democrática e da transparência na gestão dos recursos ambientais, a partir da obrigatoriedade da publicização das ferramentas de avaliação de impacto e do licenciamento ambiental (artigo 225, inciso IV), além da participação da sociedade e do efetivo controle social sobre as políticas públicas, com o acesso à informação e à educação ambiental (artigo 225, inciso VI) (BRASIL, 2014).

As propostas da $\mathrm{CDB}$, no que referem ao direito ao meio ambiente sustentável e diversificado a partir de uma nova concepção de economia, que relaciona custos e benefícios, diante da consideração das variáveis ambientais e da participação política, com o equilíbrio Versão em português recebida em 08/01/2014, aceita em 08/01/2015, e autorizada para publicação em 29/06/2015 


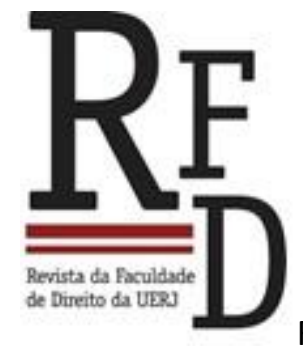

14

REVISTA DA FACULDADE DE DIREITO DA UERJ- RFD, N. 27, 2015

entre o uso dos recursos naturais e o crescimento demográfico, foram acatadas pelo Brasil (DIEGUES, 1992).

Da mesma forma que a Convenção evidenciou a preocupação com o desenvolvimento econômico, principalmente, nos países pobres, e pela busca da qualidade desse crescimento, o Brasil adotou a inquietação com a reversibilidade do decréscimo das reservas naturais e da diversidade biológica, em contraponto com o constante crescimento populacional, onde a conservação dos recursos naturais é a condição básica para o desenvolvimento sustentável (CASTELLS, 1999), pois a problemática ambiental, mais que uma crise ecológica, é um questionamento do pensamento e do entendimento da civilização ocidental (LEFF, 2003).

Tanto a Convenção sobre a Diversidade Biológica, quanto às previsões contidas na Carta Magna brasileira, em especial, no artigo 225, são importantes instrumentos, de cunho internacional e nacional, respectivamente, para se promover a proteção dos ambientes naturais que ainda estão preservados, e a recuperação dos espaços ecológicos atingidos, de alguma forma, pela ação humana, pois elencam vários dispositivos mandamentais, com vinculação direta a todos os setores - poderes públicos e sociedade - para a preservação do meio ambiente, inclusive, visando a proteger um direito intergeracional.

Portanto, a proposta do desenvolvimento sustentável, contida nessas Normas, é aquela baseada no ecodesenvolvimento, capaz de satisfazer as necessidades presentes e, ao mesmo tempo, assegurar que as futuras gerações, igualmente, possam usufruir de uma natureza sadia, por conta da preservação da diversidade biológica, com a ampla concretização do direito humano ao meio ambiente, ecologicamente, equilibrado.

\section{CONSIDERAÇÕES FINAIS}

O presente trabalho buscou pontuar, brevemente, os principais eventos voltados à proteção ambiental em nível internacional, e o quão importante são as normas legais de abrangência internacional, como a Convenção sobre a Diversidade Biológica, para a preservação do meio ambiente. Tal Documento visou, principalmente, a prever medidas que possibilitem o uso racional da diversidade biológica e a busca pela sustentabilidade econômica 
dos países, favorecendo um desenvolvimento sustentável como requisito fundamental para assegurar o bem-estar e o gozo dos recursos naturais pelas futuras gerações.

A partir da ratificação dessa Convenção, o Brasil comprometeu-se a observar as determinações, nela contidas, evidenciando-se o teor do artigo 225 da Constituição Federal, de crucial importância para a preservação do meio ambiente equilibrado, ante a abrangência de sua tutela, determinando a preservação, a recuperação e a preocupação com a manutenção do meio ambiente, considerando o direito intergeracional e uma obrigação de todos.

Além disso, restou evidenciado que a busca por um meio ambiente sustentável e equilibrado é cosmopolita, comum a todas as pessoas e de responsabilidade de todas as nações, haja vista o fato de a biodiversidade desconhecer fronteiras políticas. Assim, a Convenção sobre a Diversidade Biológica representou um marco a fim de assegurar à toda a humanidade gerações presentes e futuras - uma vida mais salutar, e, da mesma forma, na seara nacional, das normas constitucionais regentes, na busca pelo ecodesenvolvimento.

\section{REFERÊNCIAS}

ALMEIDA, Jalcione. Projetos agrícolas alternativos e de diversificação: em direção ao fim de um modelo de desenvolvimento? Paris: Mémoire de D.E.A.,1990.

ANTUNES, Paulo de Bessa. Direito ambiental. Rio de Janeiro: Lumen Juris, 2008.

ARENDT, Hannah. As Origens do totalitarismo. Rio de Janeiro: Documentário, 1979.

BOBBIO, Norberto. A Era dos Direitos. Rio de Janeiro: Campus, 2004.

BRANCO, Samuel Murgel. Ecossistêmica: uma abordagem integrada dos problemas do meio ambiente. São Paulo: Edgar Blücher, 1989.

BRASIL. Constituição Federal da República Federativa do Brasil. 2014. Disponível em: <http://www4.planalto.gov.br/legislacao>. Acesso em: 08 jul. 2014, 09h00min. 


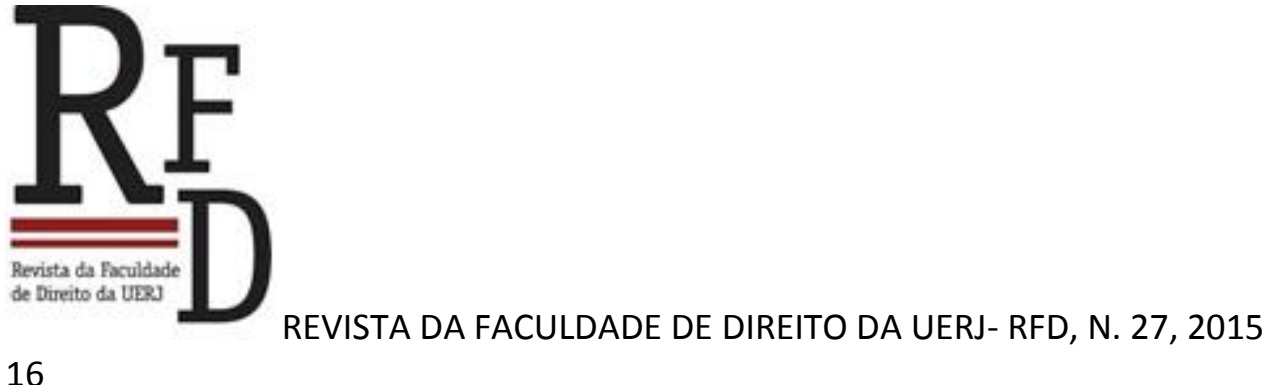

16

BRAUN, Helenice. O Brasil e os Direitos Humanos. Ijuí: Unijuí, 2002.

BRUGGER, Paula. Educação ou adestramento ambiental? Florianópolis: Argos, 2004.

CAMPOS, Gastão Wagner de Souza. Tratado de saúde coletiva. São Paulo: Hucitec, 2006.

CANOTILHO, José Joaquim Gomes; LEITE, José Rubens Morato. Direito Constitucional Ambiental Brasileiro. São Paulo: Saraiva, 2007.

CAPRA, Fritjof. Alfabetização ecológica. São Paulo: Cultrix, 2006.

CASTELLS, Manuel. O poder da identidade. São Paulo: Paz e Terra, 1999.

CAVALCANTI, Clóvis. Meio ambiente, desenvolvimento sustentável e políticas públicas. São Paulo: Cortez, 1997.

CENCI, Daniel. O direito ao ambiente ecologicamente equilibrado como direito fundamental da pessoa humana. In: BEDIN, Gilmar Antônio (Org.) Cidadania, direitos humanos e equidade. Ijuí: Unijuí, 2012.

COMUNIDADE EUROPEIA. Convenção sobre a Diversidade Biológica: implementação na União Europeia. Luxemburgo: Serviço das Publicações Oficiais das Comunidades Europeias, 2006.

CORREA, Darcísio; OLIVEIRA, Janassana I. A. de; SANTOS, Marcelo L. dos; SPAREMBERGER, Raquel F. L. Cidadania, Biodiversidade e Identidade Cultural na Reserva Indígena do Guarita. Ijuí: Unijuí, 2007.

CUNHA, Manoela Carneiro da. Populações tradicionais e a Convenção da Diversidade Biológica. In: BALDI, César Augusto (Coord.) Direitos Humanos na Sociedade Cosmopolita. Rio de Janeiro: Renovar, 2004. 


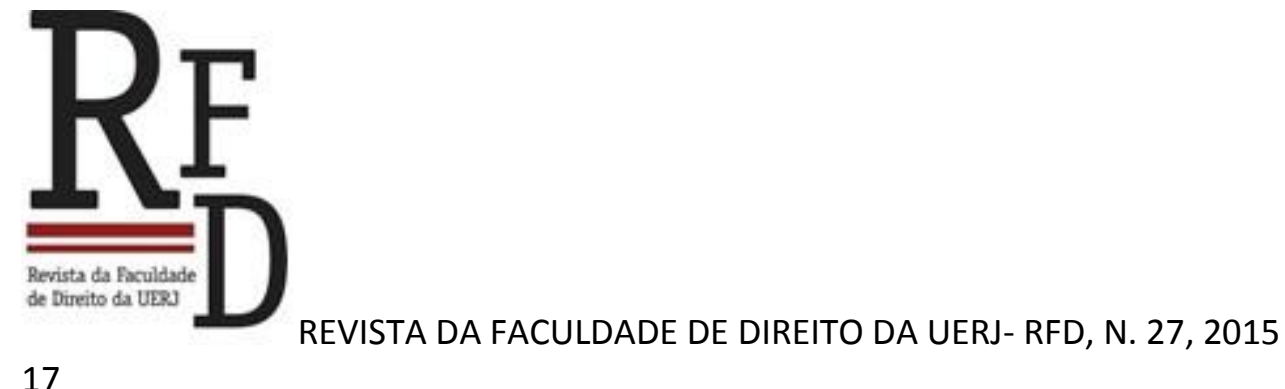

17

DERANI, Cristiane. Direito Ambiental Econômico. São Paulo: Max Limonad, 1997.

DIEGUES, Antônio Carlos Sant'Ana. Desenvolvimento sustentável ou sociedades sustentáveis: da crítica dos modelos aos novos paradigmas. Revista São Paulo em Perspectiva. São Paulo: Fundação Seade, pp. 22-29, 1992.

GANEM, Roseli Senna. Conservação da Biodiversidade das reservas de caça. Brasília: UnB, 2012. Disponível em: <http://www.aslegis.org.br/aslegisoriginal/images/stories /artigospessoais/conservacao-biodiversidade/conservacao-da-biodiveridade-das-reservas-dacaca-a-convencao.pdf. 2012>. Acesso em: 14 jul. 2014, 10h00min.

ISAIA, Elenise Maria Bezerra. Ito. Geoprocessamento e educação ambiental no processo de gestão do conflito socioambiental do Arroio Cadena. Santa Maria: UFSM, 2004.

LAYRARGUES, Philippe Pomier. Do ecodesenvolvimento ao desenvolvimento sustentável: evolução de um conceito? Rio de Janeiro: Revista Proposta, 1997.

LE GUYADER, Hervé. La biodeversité: un concept flou ou une realité scientifique? Le courier de l'environment de l'INRA. Paris: INRA, n. 55, 2008.

LE PRESTE, Philippe. Ecopolítica internacional. São Paulo: Senac, 2000.

LEFF, Enrique. Pensar a complexidade ambiental. In: LEFF, Enrique (Org.). A complexidade ambiental. São Paulo: Cortez, 2003.

MACHADO, Paulo Afonso Leme. Direito Ambiental Brasileiro. $21^{\mathrm{a}}$ ed. São Paulo: Malheiros, 2013.

MANCINI, Pasquale Stanislao. Direito Internacional. Ijuí: Unijuí, 2003.

MENDES, Armando Dias. Breve itinerário dos ecossistemas à ecopoesia: Achegas para o seu traçado. São Paulo: Brasiliense, 1993. 
MINISTÉRIO DO MEIO AMBIENTE. Convenção sobre a Diversidade Biológica. Disponível em: <http://www.mma.gov.br/biodiversidade/convencao-da-diversidadebiologica.> Acesso em: 10 ago. 2014, 15h30min.

PANNETON, Francine. Formation relative à l'environnement: Design de formation d'um module de formation en gestion environnementale intégrée à l'intention des decideurs de la PME. Montreal: Universidade de Quebec, 1994.

PASSOS, Priscilla Nogueira Calmon de. A Conferência de Estocolmo como ponto de partida para a proteção internacional do meio ambiente. Revista Direitos Fundamentais \& Democracia, vol. $6, \quad \mathrm{n}^{\circ} . \quad 2, \quad 2009 . \quad$ Disponível em: http://revistaeletronicardfd.unibrasil.com.br/index.php/rdfd/article/viewArticle/18. Acesso em: 10 ago. 2014, 16h00min.

QUINTÃO, Ângela Tresinari Bernardes. Evolução do conceito de parques nacionais e sua relação com o processo de desenvolvimento. Brasil Florestal, v. 13, n. 54, p. 13-28, abr./ maio/jun. 1983.

SACHS, Ignacy. Ecodesenvolvimento: crescer sem destruir. São Paulo: Vértice, 1986.

SANTILLI, Juliana. Os novos direitos socioambientais. Revista Direito e Justiça - Reflexões Sociojurídicas - Ano 9 - nº. 9, pp. 173 - 200, 2006.

SANTOS, Boaventura de Sousa; MENESES, Maria Paula G.; NUNES, João Arriscado. Introdução: Para ampliar o cânone da ciência: a diversidade epistemológica do mundo. In: SANTOS, Boaventura de Sousa (Org.). Semear outras soluções: os caminhos da biodiversidade e dos conhecimentos rivais. Rio de Janeiro: Civilização Brasileira, 2005.

SEGURA, Denise de Souza Baena. A educação ambiental na escola pública: da curiosidade ingênua à consciência crítica. São Paulo: FAPESP, 2001.

SOUZA, José Dalmo de; DAL RI, Marlene K. Perspectivas do mercado nacional e internacional e possibilidades de acesso e participação. In: BASSO, David; 


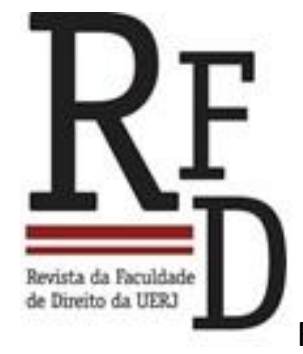

19

REVISTA DA FACULDADE DE DIREITO DA UERJ- RFD, N. 27, 2015

TRENNEPOHL, Dilson (Org.) Planejamento estratégico de arranjos produtivos locais. Ijuí: Unijuí, 2012.

UNEP - UNITED NATIONS ENVIRONMENT PROGRAMME. Sustaining life on Earth: how the Convention on Biological Diversity promotes nature and human well-being. Secretariat of the Convention on Biological Diversity: United Kingdom, 2000. Disponível em: $<$ https://www.cbd.int/doc/publications/cbd-sustain-en.pdf $>$. Acesso em: 08 jul. 2014, $10 \mathrm{~h} 10 \mathrm{~min}$.

VARELLA, Marcelo Dias; ROCHA, Eliana Fontes Fernando Galvão da Rocha. Biossegurança e biodiversidade: contexto científico e regulamentar. Belo Horizonte: Del Rey, 1999.

WILSON, Edward. O. Biodiversidade. Rio de Janeiro: Nova Fronteira, 1997. 